\title{
Nazi Almanya'sında Nazizm İdeolojisiyle Şekillenen Kitap Okuma Kültürünün Sinemadaki Sunumu: "Kitap Hırsız»" Filminin Göstergebilimsel Analizi
}

\author{
The Presentation of Book Reading Culture Shaped with Nazism Ideology in Nazi \\ Germany in Cinema: The Semiotic Analysis of the Film "The Book Thief"
}

\author{
Ebru Gülbuğ Erol *
}

$\ddot{\boldsymbol{z}_{z}}$

Antikomünist, antikapitalist, antisemitist ve ırkçılık temelli Nazizm ideolojisi, Nasyonal Sosyalist Alman Işşi Partisi'nin (NSDAP) iktidarda bulunduğu dönemde (1933-1945) Almanya'da sosyal, siyasal, ekonomik ve kültürel hayata doğrudan etki etmişstir. NSDAP'nin iktidardan uzaklaştırllmasından sonra Nazizm ideolojisinin etkisi altındaki Almanya'yı konu alan çok sayıda film çekilmişs ve ideolojinin Alman toplumundaki yansımaları ortaya konulmaya çalışılmıştır. Bu filmlerden biri de Brian Percival yönetmeliğindeki 2013 yılı Almanya-ABD ortak yapımı Kitap Hırsızı (The Book Thief) filmi olmuştur. Filmde Nazizm ideolojisi altında Almanya'daki kitap okuma kültürünün ne yönde şekillendiği konu edilmiştir. Çalışmada Kitap Hırsızı filmi göstergebilimsel açıdan analiz edilerek, filmde Nazizm ideolojisi altında Alman eğitiminin ve beraberinde kitap okuma kültürünün ne yönde şekillendiğinin ortaya konulması amaçlanmıştır. Çalışma kapsamında filmin göstergebilimsel analizi, ABD'li dilbilimci Charles Sanders Peirce'in göstergebilim anlayışı ve İngiliz dilbilimci Geoffrey Leech'ın anlamlandırmanın yedi türü ışığında gerçekleştirilmiştir. Çalışmanın analizinde filmde ana karakter Liesel'in Nazi rejimi altında korku ve basklya maruz kaldı̆̆ına ve insanların özgür şekilde kitap okumasının engellendiğine yönelik kurgunun oluşturulduğu ortaya konulmuştur. Diğer yandan filmde Nazi Almanya'sında Nazizm ideolojisinin ögretilerini yansitan veya Nazi rejiminin sansürüne uğramayan kitapların okunmasının da teşvik edildiği sonucuna ulaşılmıştır.

Anahtar Sözcükler: Kitap okuma kültürü; sinema; kitap; film; Nazi Almanya'sl.

\section{Abstract}

The anti-communist, anti-capitalist, anti-semitic and racist-based Nazism ideology had a direct impact on social, political, economic and cultural life in Germany during the period of the National Socialist German Workers Party (NSDAP) (1933-1945). After the removal of the NSDAP from power, many films about Germany under the influence of Nazism ideology were shot and the reflections of the ideology in German society were tried to be revealed. One of these films was the 2013 German-US co-production The Book Thief, directed by Brian Percival. In the film, it is the subject of how the book reading culture in Germany was shaped

\footnotetext{
* Prof. Dr., Alanya Hamdullah Emin Paşa Üniversitesi. E-posta: egerol@ahep.edu.tr Prof.Dr., Alanya Hamdullah Emin Pasa University.E-posta: egerol@ahep.edu.tr
}

Geliş Tarihi - Received: 10.02 .2021

Kabul Tarihi - Accepted: 24.03.2021 
Nazi Almanya'sında Nazizm İdeolojisiyle Şekillenen Kitap Okuma Kültürünün Sinemadaki Sunumu: “Kitap Hirsızı" Filminin Göstergebilimsel Analizi

The Presentation of Book Reading Culture Shaped with Nazism Ideology in Nazi Germany in Cinema: The Semiotic Analysis of the Film "The Book Thief"

under Nazism ideology. The aim of this study was to analyze the film The Book Thief in terms of semiotics and to reveal how German education and book reading culture were shaped under Nazism ideology. Semiotic analysis of the film was made in the light of US linguist Charles Sanders Peirce's semiotics understanding and British linguist Geoffrey Leech's seven types of signification within the scope of the study. In the analysis of the study, it was revealed that the main character Liesel was subjected to fear and pressure under the Nazi regime and that people were prevented from reading books freely in the film. On the other hand, it was concluded that it was encouraged reading books that reflected the teachings of the Nazi ideology or were not censored by the Nazi regime in Nazi Germany in the film.

Keywords: Book reading culture; cinema; book; film; Nazi Germany.

\section{Giriş}

İktidarlar, kitleleri kendi düşüncelerine göre şekillendirmeyi ve kendi ideolojilerini kitlelere benimsetmeyi amaçlayabilmektedir. Özellikle basın ve yayın üzerinde mutlak denetim sağlayan egemen güçler, insanların okuma kültürünün şekillenmesinde önemli bir rol üstlenebilmekte, insanların neleri okuyup neleri okumamaları gerektiği konusunda doğrudan etkide bulunabilmektedir. $\mathrm{Bu}$ aşamada kimi zaman gazete ve dergi yayınları sansürlenebilmekte, kitaplar yasaklanabilmekte ve yayınevleri kapatılabilmektedir. Naziler de Almanya'da iktidarda bulundukları dönemde (1933-1945), Almanya'da okunan kitaplar üzerinde kontrol kurarak Alman halkının kitap okuma kültürünün şekillenmesinde doğrudan etkili olmaya çalışmıştır. Nazi Almanya'sında Nazizm ideolojisinin öğretilerini yücelten ve benimseten kitaplar ön plana çıkarılmış, Nazi rejimi tarafından tehdit olarak sunulan kitaplar ise kitap yakma etkinliğinde yok edilmiştir. Bu şekilde Naziler, Alman halkının okuyacağı kitaplar üzerinde doğrudan belirleyici bir rol oynamıştır. Nazi Almanya'sında kitapları konu alan çeşitli yayınlar gerçekleştirilmiştir. Brian Percival yönetmenliğindeki 2013 AlmanyaABD ortak yapımı Kitap Hırsızı (The Book Thief) filmi de Nazilerin Almanya'da kitap okuma kültürünün şekillenmesini beyaz perdeye yansıtmıştır. Filmde Liesel adlı bir kız çocuğunun hayatı üzerinden Nazi Almanya'sında Nazizm ideolojisi üzerinden şekillenen eğitim ve kitap okuma kültürü konu edilmiştir.

Uluslararası çalışmalar içerisinde okuma kültürünü konu alan çok sayıda akademik çalışma bulunmaktadır (Schlott, 1984; Verók, 1999; Misiūnas ve Pischel, 2002; Ifedili, 2009; Fabunmi ve Folorunso, 2010; Leu, 2010; Daniels ve Steres, 2011; Buchanan, 2012; Azmi, 2013). Bu çalışmalar içerisinde: Lyons (2008), on dokuzuncu yüzyıl Fransa'sında okuma kültürü ve yazma uygulamalarını; Howley (2018), Aulus Gellius ve Roma okuma kültürünü; Akindele (2012), okuma kültürü, ebeveyn katılımı ve çocukların gelişimini; StrangerJohannessen (2014), Uganda'da kütüphane aracılığıyla okuma kültürünün teşvik edilmesini; Joubert vd. (2014), kırsal bir ortaokulda okuma kültürünün oluşturulmasını; Egong (2014), okuma kültürü ve akademik başarıyı; Ilogho (2015), Nijeryalı çocuklar arasında okuma kültürünü teşvik etmede resimli kitapların rolünü; Loh (2015), Singapur'da okulda okuma kültürünün inşa edilmesini; Olasehinde vd. (2015), okuma kültürünün teşvik edilmesini; Dick (2006), kitap tarihi, kütüphane tarihi ve Güney Afrika'nın okuma kültürünü; Kamalova ve Koletvinova (2016), öğrencilerin okuma ve okuma kültürünün geliştirilmesi sorununu; Loh 
vd. (2017), okul kütüphanesi aracılığıyla okuma kültürünün oluşturulmasını; Wema (2018), Tanzanya'daki yüksek öğrenim kurumlarındaki öğrenciler arasında okuma kültürünü ve Heidtmann (2002), okuma kültüründeki değişiklikleri incelemiştir. Okuma kültürüne ilişkin farklı konular üzerinden geniş bir yelpazede akademik çalışmaların yapıldığı ortaya çıkmaktadır.

Okuma kültürü gibi Nazizm ideolojisi üzerine de çok sayıda akademik çalışma gerçekleştirilmiştir (Kirchheimer, 1941; Dülffer, 1976; Mason, 1977; Taylor, 1981; Wagner, 1981; Farias, 1989; Paskow, 1991; Herf, 1993; Dunlop, 1996; Rockmore, 1997; Young, 1998; Herkommer, 2008; Geyer ve Fitzpatrick, 2009; Kuhl, 2002; Eley, 2013; Patel ve Reichardt, 2016; Zakić, 2017). Bu çalışmalarda da: Collingwood (1940), Hansen (1981), Nazizm ve Faşizm'i; Loomis ve Beegle (1946), Nazizm'in kırsal alanlarda yayılmasını; Sternhell (1973), Frosh (2015), antisemitizm ve Nazizm'i; Stein (1988), Nazizm'in köklerini; Fischer (1991), Harsch (1993), Hamilton (2003), Campbell (2004), Häberlen (2013), Falter (2014), Nazizm'in yükselişini; Berman (1992), Herman (2001), Yahudiler ve Nazizm'i; Weindling (1993), ulusal birleşme ve Nazizm arasında sağlık, ırk ve Alman siyasetini; Davidson (1997), Nazizm'in doğuşu ve yükselişini; Ian (1997), Stalinizm ve Nazizm'i; Geary (2002), Hitler ve Nazizm'i; Kirk (2002), Nazizm ve işçi sınıfını; Mühlberger (2003), Nazizm'in sosyal temellerini; Stone (2003), İngiltere'deki Nazizm'e tepkileri; Forti (2006), ırkçılık ve Nazizm'i; Stuart (2006), sosyalizm, milliyetçilik ve Nazizm'i; Neumann (2009), Nazizm'in yapısı ve pratiğini; Giles (2014), Nazizm ve öğrencileri incelemiştir.

Uluslararası alanda Nazi Almanya'sında sinemayı inceleyen de çeşitli akademik çalışmalar bulunmaktadır (Padover, 1939; Hull, 1993; Rentschler, 1996; Schulte-Sasse 1996; Petro, 1998; Witte, 1998; O'Brien, 2004; Rothberg, 2009; Ascheid; 2010; Hake, 2010; Shandley, 2010; Hochscherf ve Vande Winkel, 2016). Diğer yandan son y1llarda ulusal çalışmalar içerisinde kitapları (Erol, 2020) ve okuryazarlığı konu alan çeşitli akademik çalışmalar yapılmaktadır (Çakı vd., 2020; Gazi vd., 2020). Çalışmada ise NSDAP iktidarı döneminde Nazizm ideolojisi altında Almanya'da şekillenen kitap okuma kültürünün sinemaya yansımasının ortaya konulmasına çalışılmıştır. Çalışma kapsamında "Nazizm ideolojisi, Alman halkının kitap okuma kültürü üzerinde ne gibi bir rol oynamıştır?" sorusunun yanıtlanması amaçlanmıştır. $\mathrm{Bu}$ amaçla çalışmada Kitap Hırsızı filmi göstergebilimsel açıdan incelenerek, filmdeki görsel, yazılı ve sözlü göstergeler üzerinden verilen mesajların ortaya konulmasına çalışılmıştır. Çalışmada elde edilen bulgular, Nazi Almanya'sında okuma kültürüne ilişkin bilgi vermesi, Nazizm ideolojisinin kitaplar üzerindeki etkisini yansıtması ve Nazi Almanya'sındaki okuma kültürünün sinemadaki sunumuna ışık tutması bakımından önem taşımaktadır.

\section{Nazizm İdeolojinde Eğitim}

Nasyonal Sosyalist Alman İşçi Partisi (NSDAP), tarafından benimsenen Nazizm ideolojisi (Goodrick-Clarke, 1993, s. 7), antisemitik, antikapitalist, antikomünist ve etnik Alman milliyetçiliğini savunan bir dünya görüşüdür. Nazizm ideolojisi, NSDAP'nin Almanya'da iktidarda olduğu dönemde (1933-1945) Alman toplumsal, siyasal ve ekonomik hayatında etkili olmuştur. Nazizm ideolojisinde Komünizm ideolojisi ve Yahudiler tehdit olarak sunulmuştur. Diğer yandan Nazizm ideolojisinde devlet vurgusu ön planda olmuş ve bireyin 
Nazi Almanya'sında Nazizm İdeolojisiyle Şekillenen Kitap Okuma Kültürünün Sinemadaki Sunumu: “Kitap Hirsızı" Filminin Göstergebilimsel Analizi

The Presentation of Book Reading Culture Shaped with Nazism Ideology in Nazi Germany in Cinema: The Semiotic Analysis of the Film "The Book Thief"

varlığının temelinde devletin olduğu ileri sürülmüştür (Macit, 2007, s. 75). Nazi propagandası ideolojinin öğretilerini kitlelere benimsetmeye çalışılmış, bu aşamada Nazizm ideolojisini yücelten söylemlere yer verilmiştir. Nazi Almanya'sında Nazizm ideolojisi, pek çok alanda olduğu gibi eğitim alanında da etkisini hissettirmiştir. Nazi Almanya'sında, öğrencilerin Nazizm ideolojisinin öğretilerini benimsemesi amaçlanmış, bu amaçla NSDAP bünyesinde, Hitler Gençliği (Hitlerjugend, HJ) adı verilen gençlik birimi oluşturulmuştur. HJ, NSDAP'nin paramiliter birimi olan SA'nın (Taarruz Bölüğü / Sturmabteilung) gençlik kolları olarak örgütlenmiştir. HJ üyeleri, SA'lar gibi kahverengi bir gömlek giymiş ve üstünde gamalı haç olan kol bandı takmıştır (Mcnab, 2015, s. 379-380).

Nazizm ideolojisi altında eğitim alan erkekler iyi bir vatansever ve asker olarak idealize edilmiştir. Bu aşamada Nazi propagandası Alman erkeklerin, NSDAP'nin bir diğer paramiliter birimi olan SS'e (Koruma Timi / Schutzstaffel) katılmasını teşvik etmiştir. İkinci Dünya Savaşı sırasında da Alman gençleri, askerlik eğitimine tabi tutulmuş ve Almanya'nın asker ihtiyacının artmaya başladığı dönemlerde pek çok Alman genci cephelerde savaşmaya gönderilmiştir. Diğer yandan, Nazizm ideolojisi altında verilen eğitimde spor faaliyetleriyle öğrencilerin güçlü ve sağlıklı bireyler olarak yetiştirilmesi de amaçlanmıştır. Bu amaçla 27 Temmuz 1934 tarihinde Nazi Almanya'sında Beden Eğitimi için Nasyonal Sosyalist Reich Birliği (Nationalsozialistischer Reichsbund für Leibesübungen) kurulmuştur. Nazizm ideolojisinde ari ırk vurgusu yapılmakta ve Alman 1rkının, ari ırk olduğu düşüncesi ön plana çıkarılmaktadır. Yahudiler, ari irk için tehdit olarak değerlendirilmekte (Passmore, 2014, s. 146) ve Nazi propagandasında, Yahudilere karşı olumsuz söylemlere yer verilmektedir. 1933 ile 1945 arasında, genç Almanlar okullarda, (ders dışı) HJ'de ve radyo ve film aracılığıyla Yahudi karşıtı ideolojiye maruz kalmıştır (Voigtländer ve Voth, 2015, s. 7931).

Nazizm ideolojisi altında verilen eğitimde liderin yüceltilmesi ve lidere mutlak bağlllık ön planda tutulmaktadır. HJ'de Führer (Lider) olarak adlandırılan Nazi Almanya'sının devlet başkanı Adolf Hitler'e bağlılık vurgulanmakta ve Hitler'e yönelik kült liderlik propagandası gerçekleştirilmektedir. Bu aşamada Alman gençlerinin Hitler'in emirlerine itaat etmesi teşvik edilmiştir. Ayrıca Alman öğrencileri gibi Alman öğretmenlerin de Nazizm ideolojisini benimsemesine önem verilmiştir. Bu amaçla 21 Nisan 1929 tarihinde Nasyonal Sosyalist Ögretmenler Ligi (Nationalsozialistische Lehrerbund, NSLB) kurulmuştur. Diğer yandan NSLB tarafından Yardım Et! (Hilf Mit!) adında öğrencilere yönelik eğitim ve propaganda içerikli nasyonal sosyalist bir gazete yayınlanmıştır. Almanya'nın 1945 yılında kayıtsız şartsız teslim olmasından sonra (Hart, 2015, s. 945), Nazizm ideolojisi Almanya'da etkinliğini kaybetmiştir. Denazifikasyon (Nazilerden Arındırma) sürecinde de Naziler tarafından kurulan eğitim odaklı örgütler kapatılmıştır.

\section{Nazi Almanya'sında Kitap Okuma Kültürünün Şekillenmesi}

Naziler, Almanya'da iktidara geldikten sonra basın ve yayın üzerinde sıkı bir denetim kurmuştur. Bu aşamada Naziler, Almanya'da Nazi rejimine ve Nazizm ideolojisine karşıt yayınları hedef almış ve bu tür yayınlara karşı yasakçı bir tutum içerisine girmiştir. Özellikle Naziler, ideolojilerine muhalif olan kitaplara karşı hareket geçmiş ve bu kitapların Alman halkı tarafından okunmamasına çalışmıştır. Nazi Almanya'sına yönelik eleştirileri, Marksizm, 
Komünizm ve Bolşevizm literatürü, pasifist edebiyatı, ırk ilkelerine zarar verdiği düşünülen cinsellik ve cinsel eğitim üzerine yazıları içeren kitaplar Nazilerin hedefinde olmuştur. Bu aşamada Naziler tarafindan pek çok yazar yasaklı hale getirilmiştir. Yasaklı yazarların resmi listesi de Halkı Aydınlatma ve Propaganda Bakanlığı tarafından yayınlanmıştır. Bakanlık, mevcut kitapları yasaklayabilmekte ve bunlara el koyabilmekte, isterse yayın öncesi sansür uygulayabilmekte ve belirli yazar ve yayıncıların sınır dışı edilmesine karar verebilmektedir (Sturge, 2002, s. 154).

Nazi rejimi, kitaplar konusunda kararlılığını vurgulamak ve Alman halkının Nazizm ideolojisine karşıt kitapları okumasını engellemek için kitap yakma etkinliği düzenlemiştir. Etkinlik, Alman Öğrenci Birliği’nin (Deutsche Studentenschaft, DSt) katılımıyla gerçekleşmiş ve pek çok kitap etkinlik kapsamında hedef alınmıştır. Alman olmayan ruha karşı eylem (Aktion wider den undeutschen Geist) olarak gerçekleşen kitap yakma etkinliğinde Yahudi, komünist, sosyalist ve anarşist yazarların eserleri yakılmıştır. Kütüphaneci Wolfgang Herrmann'ın Kara Listeler'i (Schwarze Listen) yakılacak eserlerin seçilmesinde önemli bir rol oynamıştır. Birçok şehirde kitaplar yakılmış (Pohlmann, 2012, s. 193) diğer yandan Nazilerin kitap yakma etkinliği, Alman halkı nezdinde güç gösterisi haline gelmiş ve etkinlikle birlikte rejimin karşı olduğu kitapların okunmasının engellenmesinde Nazilerin ne kadar kararlı olduğu ortaya konulmuştur. Pek çok yazar ve bilim insanının çalışması yasaklanmış, eserlerinin kütüphanelerde, okullarda ya da üniversitelerin müfredatlarında bulunmas1 engellenmiştir. Nazilerin kitaplar üzerinde kurduğu denetim sonucunda Alman halkı yalnızca rejimin kendilerine izin verdiği kitapları okuma imkânı bulmuştur. Bu aşamada Hitler'in Kavgam (Mein Kampf) kitabı ve Nazizm ideolojisini yücelten yayınlar ön plana çıkmıştır.

Naziler, kitaplara olduğu gibi kütüphanelere de müdahale etmiştir. 1933 ile 1939 arasındaki altı yılda, Nazi rejimi, Alman halk kütüphanelerini dönüştürmeye çalışmış, bu amaçla önce sıkı bir sansür uygulamış ve şüpheli görüşlere sahip personeli politik olarak güvenilir kişilerle değiştirmiş, ardından beş yüz veya daha fazla nüfusa sahip her köye bir halk kütüphanesi getirmek için inşaat programı başlatmıştır. Rejim, kütüphane raflarını propagandayla doldurdumuş ve kütüphane kullanımı artırmaya yönelik programları teşvik etmiştir. Politikayı uygulamak için ayrıntılı bir idari yapı oluşturulmuş, eski fikirler ve değerler yenileriyle değiştirilmiştir. Tabii ki en önemlisi, kütüphanenin artık bir Nazi halk kütüphanesi haline geldiği ilkesi olmuştur (Stieg, 1992, s. 23).

\section{Dil, Kültür ve Sanat İlişkisi}

Ülke yönetiminde bulunan kimi egemen güçler kendi ideolojik söylemlerini kitlelere benimsetmek için kitle iletişim araçlarını propaganda amacıyla etkin bir şekilde kullanabilmektedir. Egemen güçlerin topluma dayatmak istedikleri düşüncelerin medyada kullanılan dil üzerinden kitlelere aktarılması ve benimsetilmesi amaçlanabilmektedir. $\mathrm{Bu}$ aşamada iktidar, kültür ve sanat faaliyetlerinden yararlanabilmekte ve kitlelerin okudukları kitaplardan izledikleri filmlere kadar pek çok alanda ideolojik söylemlerini kitlelere empoze etmeye çalışabilmektedir. Böylece çeşitli kültürel ve sanatsal faaliyetler üzerinden egemen güçler, kitlelere neyin doğru neyin yanlış, kimin dost kimin düşman olduğuna yönelik alg1 oluşturmayı hedefleyebilmektedir. Egemen güçler, kendi düşüncelerinin toplumda hakim olabilmesini sağlamak için farklı düşüncelere sahip yayınlara yönelik sansür 
Nazi Almanya'sında Nazizm İdeolojisiyle Şekillenen Kitap Okuma Kültürünün Sinemadaki Sunumu: "Kitap Hirsızı" Filminin Göstergebilimsel Analizi

The Presentation of Book Reading Culture Shaped with Nazism Ideology in Nazi Germany in Cinema: The Semiotic Analysis of the Film "The Book Thief"

uygulayabilmektedir. Özellikle egemen güçler kendi düşüncelerine karşı olan yayınların kitlelerle buluşmasını önlemeye yönelik sıkı politikalara girişebilmektedir. Fransız dilbilimci Roland Barthes, gösteriler, sporlar, haberler ve oyunlar gibi çeşitli ortamlarda iktidarın varlığının görüldüğünü belirtmektedir (Barthes, 2015, 2. 45). Bu süreçte kültür ve sanat faaliyetleri içerisinde egemen güçlerin kullandığı dil ortaya çıkabilmekte ve günlük hayatın çeşitli anlarında insanlar egemen güçlerin diline doğrudan maruz kalabilmektedir.

\section{Yöntem}

Çalışmada Kitap Hirsızı filmi, nitel araştırma yöntemlerinden göstergebilim yöntemi kullanılarak incelenmiştir. Çalışma kapsamında Nazi Almanya'sındaki eğitimi ve kitapları konu alan film içerisindeki dokuz kısım, ABD'li dilbilimci Charles Sanders Peirce'in (18391914) göstergebilim anlayışı ve İngiliz dilbilimci Geoffrey Leech'ın (1936-2014) anlamlandırmanın yedi türü ışığında analiz edilmiştir. Çalışmada Peirce'in göstergebilim kavramları üzerinden filmdeki göstergelerin açıklanmasına, Leech'in anlamlandırma türleri üzerinden de film üzerinden verilen mesajların ortaya konulmasına çalışılmıştır. Göstergebilim, çalışmanın konusunu değil yalnızca yöntemini oluşturduğu için her iki dilbilimcinin de göstergebilim anlayışları çalışmada kapsamlı olarak ele alınmamıştır. Bu aşamada çalışmada filmde yer alan görsel, sözlü ve yazılı göstergelerin analizinde kullanılan kavramlar konusunda genel bilgi verilmiştir.

Peirce'in göstergebilim analizinde görüntüsel gösterge, belirtisel gösterge ve simge olmak üzere üç kavram ön plana çıkmaktadır. Görüntüsel gösterge, göstergelerin insanlar tarafından doğrudan algılanan anlamlarını ifade etmektedir. Belirtisel gösterge ise bir kavram veya durumun oluş nedeninin başka bir kavram veya durum ile ilişkilendirilmesini açıklamaktadır (Fiske, 2017, s. 133). Belirtisel göstergede bir olayın nedeni başka bir olayla ilişkilendirilmektedir. Simge de aralarında benzerlik bulunmayan iki kavramdan birinin diğerini temsil etmesini ifade etmektedir. Bu aşamada simge olarak kullanılan göstergenin bir kavram veya bir durumu temsil etmesi insanlar arasındaki uzlaşı sonucunda mümkün olmaktadır.

Leech'in de göstergebilim analizinde anlamlandırmanın yedi türü ön plana çıkmaktadır. Bunlar sırasıyla kavramsal, yan anlamsal, toplumsal, duygusal, yansitıcı, eşdizimsel ve konusal anlamı ifade etmektedir. Kavramsal anlam, bir kavramın insanların ilk akla gelen anlamını ifade etmektedir. Örneğin bir gülün çiçek olarak aktarılması onun kavramsal anlamını vurgulamaktadır. Bu anlamın dilbilim iletişiminde merkezi faktör olduğu varsayılmıştır (Umagandhi ve Vinothini, 2017, s. 71). Yan anlamsal anlam ise kavramın kültürden kültüre şekillenen ikinci anlamını açıklamaktadır. Örneğin bir gül, kültür içerisinde oluşturulan anlamıyla yan anlamsal açıdan sevgiyi ifade edebilmektedir. Toplumsal anlam, mesajın hangi bağlamda kullanıldığını ifade etmektedir. Duygusal anlamda da iletişim sürecinde kaynağın duygularına odaklanılmaktadır. Bu anlam türünde konuşmacının ya da yazarın hisleri ortaya konulmaktadır. Bu aşamada kaynağın mesajı hangi tavır içerisinde oluşturduğu ön planda olmaktadır. Yansitıcı anlam, farklı anlamlara sahip bir kavramın anlamlarından birinin ön plana çıkmasını ifade etmektedir. Eşdizimsel anlam, bir kavramın başka kavramlarla bir araya getirilmesi sonucu oluşan anlamlarını içermektedir. Bu aşamada 
bir göstergenin anlamı, kullanıldığı diğer gösterge veya göstergelerle farklı boyutlara taşınabilmektedir. Konusal anlam, bir konuşmacının veya yazarın mesajı sıralama, odak ve vurgu açısından düzenleme biçimini ifade etmektedir. Konusal anlama cümlelerin etken, edilgen kullanımı örnek verilebilmektedir. Cümlenin etken ve edilgen olarak kullanılmasının aynı anlamı ifade ettiği, buna karşılık iletişimsel değerlerinin farklı olabileceği belirtilmektedir (Leech, 1985, s. 20).

Jacques Derrida'nın yapısökümü, Claude Lévi-Strauss'un somutlama mantığı, Algirdas Julien Greimas'ın Eyleyenler Örnekçesi, Vladimir Propp'un biçimbilimsel yaklaşımı veya Roland Barthes'ın mit olgusu gibi çeşitli göstergebilim anlayışları bulunmaktadır. Çalışmada Peirce ve Leech'in göstergebilim modellerinin kullanılmasının temel nedeni filmde yer alan göstergelerin her iki model üzerinden kapsamlı ve anlaşılır bir şekilde ortaya konulacağı düşüncesidir. Bu aşamada filmde örneğin ikili karşıtlıklara sık yer verilmediği için Lévi-Strauss'un somutlama mantığından, mit olgusuna geniş yer verilmediği için de Barthes'ın mit olgusundan yararlanılmamıştır.

Çalışma kapsamında oluşturulan tablolar aracılığıyla ilk olarak filmin kısımları, Peirce'in göstergebilim kavramları, ardından da Leech'in anlamlandırma türleri üzerinden incelenmiştir. Elde edilen bulgular da filmin kurgusu özelinde Nazi Almanya'sındaki kitap okuma kültürü boyutunda analiz edilmeye çalışılmıştır.

\section{Bulgular ve Yorum}

Çalışmanın bu kısmında, Kitap Hırsızı filminin özetine yer verilmiş, ardından da göstergebilimsel analizi gerçekleştirilmiştir.

\section{“Kitap Hırsızı” Filminin Özeti}

Film, 1938 yılında Nazi Almanya'sındaki bir şehirde Meminger adlı küçük bir kızın yaşamını konu almaktadır. Filmin başlarında Meminger, koruyucu bir aileye teslim edilmektedir. Meminger'in koruyucu ailesi Hans Hubermann ve Rosa Hubermann'dır. Meminger, komşusu Rudy Steiner ile de arkadaş olmuştur. Liesel'in kitap okumayı çok sevmesi film boyunca ön plana çıkarılmaktadır. Filmde şehirdeki Nazi rejiminin egemenliğine vurgu yapılmakta ve şehirdekilerin Nazi rejimi tarafından "tehdit" olarak sunulan kitapları yaktığı bir etkinliğe yer verilmektedir. Etkinlikte Liesel kitap yakmaya zorlanmaktadır. Etkinlik bittikten sonra Liesel, yanık kitaplar içerisinden bir kitabı gizlice almaktadır. Liesel'in kitabı almasını belediye başkanının eşi Ilsa Hermann görmektedir. Hermann, Liesel'i evindeki kütüphanesine çağırmakta ve onun kütüphaneden kitap alıp okumasına izin vermektedir. İlerleyen süreçte belediye başkanı, Liesel'in kütüphaneye geldiğini görmektedir. Bunun üzerine Liesel de kütüphaneye gizlice girmekte ve kitap alıp okumaktadır. Bu arada Liesel'in koruyucu ailesi de Yahudi Max Vandenburg'u evlerinin bodrumunda saklamaktadır. Liesel, Vandenburg'la arkadaş olmaktadır. 
Nazi Almanya'sında Nazizm İdeolojisiyle Şekillenen Kitap Okuma Kültürünün Sinemadaki Sunumu: “Kitap Hirsızı" Filminin Göstergebilimsel Analizi

The Presentation of Book Reading Culture Shaped with Nazism Ideology in Nazi Germany in Cinema: The

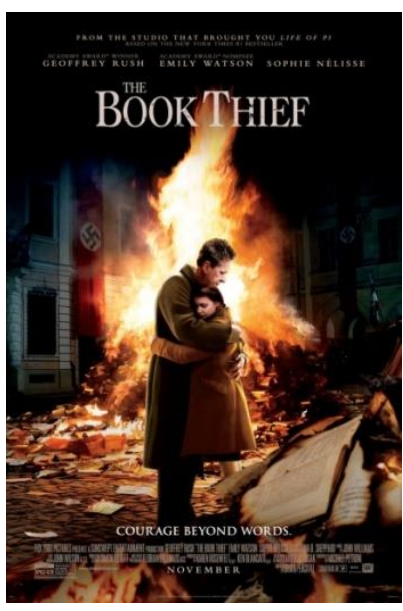

Resim 1. "Kitap Hırsızı” Filminin Afişi (Kaynak: IMDB, 2021)

\section{Kitap Okuma Kültürü̈ Bağlamında “Kitap Hırsızı" Filminin Göstergebilimsel Analizi}

Çalışmada Kitap Hırsızı filmi, her biri üçer sekansa ayrılan dokuz kısım üzerinden göstergebilimsel açıdan analiz edilmiştir.

\section{Birinci Klsım}

Görüntüsel gösterge boyutunda ele alındığında filmin birinci kısmında Liesel'in eğitim aldığ1 okula yer verildiği görülmektedir. Bu kısımda Liesel'in koruyucu ailesinin yanına yerleştikten sonra şehirdeki okulda eğitime başladığı aktarılmaktadır. Liesel'in eğitime başladığı sınıfta Hitler'in resmine ve Nazi Almanya'sının bayraklarına (Resim 2) ve Alman Irklarının Resimleri 1 (Bilder deutscher Rassen 1) adlı bir postere (Resim 2) yer verilmektedir. Okulun girişinde de Nazi Almanya'sının ve Hitler Gençliği'nin (Hitlerjugend, HJ) bayrakları (Resim 3) bulunmaktadır. Belirtisel Gösterge boyutunda incelendiğinde okulda NSDAP'nin simgelerinin bulunması, Nazilerin Alman eğitimine etkisi olduğunu yansıtmaktadır. Hitler'in fotoğrafi, Nazi rejimi ve Nazizm ideolojisini simgelemektedir. Diğer yandan Hitler'in Alman okulundaki kült liderliğine de vurgu yapılmaktadır.

\section{Tablo 1}

Birinci Kısmın Peirce'in Göstergebilim Anlayışı Üzerinden Analizi

\begin{tabular}{cc}
\hline Görüntüsel Gösterge & Liesel'in eğitim aldığı okul \\
Belirtisel Gösterge & Okulda NSDAP'nin simgelerinin bulunması, Nazilerin Alman eğitimine etkisi \\
Simge & olduğunu ifade etmektedir \\
\hline
\end{tabular}

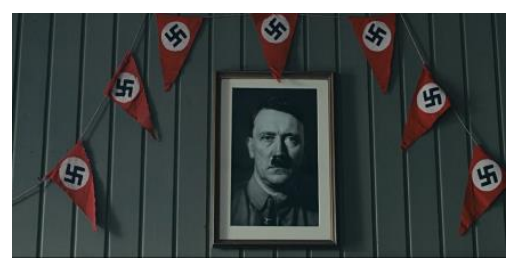

Resim 2. Birinci Sekans

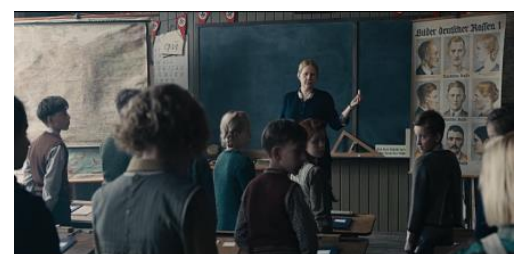

Resim 3. İkinci Sekans

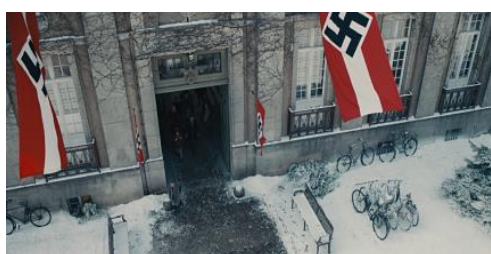

Resim 4. Üçüncü Sekans 
Kavramsal anlam açısından Alman öğrencilerin eğitim alması yansıtılmaktadır. Okuldaki Hitler resmi, HJ'nin bayrakları ve özellikle Alman Irklarının Resimleri 1 adlı poster üzerinden yan anlamsal anlam boyutunda Alman okullarında Nazizm ideolojisinin etkisi aktarılmaktadır. Toplumsal anlam açısından NSDAP iktidarında eğitim ortaya konulmaktadır. Filmin ilk kısmındaki görsel ve yazılı göstergeler üzerinden Alman eğitim sisteminde doğrudan NSDAP'nin etkili olduğuna ve Nazizm ideolojisinin rrksal fikirlerinin ön plana çıkarıldığına yönelik algı meydana gelmektedir. Duygusal anlam boyutunda egemenlik ön plana çıkarılmaktadır. Filmde Alman halkının Nazizm ideolojisini benimsediği (veya benimsetilmeye zorlandığı) ve Nazizm ideolojisinin Alman eğitimine egemen olduğu düşüncesi ortaya çıkarılmaktadır. Yansıtıcı anlam açısından Nazizm, otorite mesajı vermektedir. Nazizm'in Alman halkı üzerinde kurduğu otoriteye vurgu yapılmaktadır. Eşdizimsel anlam boyutunda Liesel'in Nazizm ideolojisi etkisinde eğitim alması yansıtılmaktadır. Bu açıdan Liesel'in eğitim sürecinin Nazizm ideolojisi altında şekillendiğine vurgu yapılmaktadır. Genel itibariyle konusal anlam açısından Nazizm ve eğitim vurgulanmaktadır. Alman eğitimi ve Nazizm arasında güçlü bir bağ kurulmaktadır.

Tablo 2

Birinci Klsmın Leech'in Anlamlandırmanın Yedi Türü Üzerinden Analizi

\begin{tabular}{ccccccc}
\hline Kavramsal & Yan anlamsal & Toplumsal & Duygusal & Yansitıcı & Eşdizimsel & Konusal \\
Anlam & Anlam & Anlam & Anlam & Anlam & Anlam & Anlam \\
Alman & Alman & & & & Liesel'in & \\
öğrencilerin & okullarında & NSDAP & & Nazizm'in & Nazizm & Nazizm ve \\
eğitim & Nazizm & iktidarında & Egemenlik & otorite mesajı & ideolojisi & eğitim \\
alması & ideolojisinin & eğitim & & vermesi & etkisinde & \\
& etkisi & & & & eğitim alması & \\
\hline
\end{tabular}

\section{İkinci Klsım}

Görüntüsel gösterge açısından incelendiğinde filmin ikinci kısmında Liesel'in okuluna ve yaşadığı şehre yer verildiği görülmektedir. Liesel'in giydiği üniformadan Liesel'in HJ'de yer aldığı anlaşılmaktadır (Resim 5). Bu arada Liesel evde boş zamanlarında kitap okumaktadır (Resim 6). Hitler'in doğum günü olduğu içinde de bulunduğu sokaktaki evlere Nazi Almanya'sının bayrakları asılmaktadır (Resim 7). Belirtisel gösterge üzerinden ele alındığında şehirde NSDAP'nin simgelerinin bulunması, Nazilerin Almanların sosyal hayatı üzerinde etkisi olduğunu yansıtmaktadır. Gamalı haçlı bayraklar, Nazi rejimini ve Nazizm ideolojisini simgelemektedir. Filmde Liesel'in hayatının doğrudan Nazizm ideolojisinin etkisi altında olduğuna vurgu yapılmaktadır.

\section{Tablo 3}

\section{İkinci Kısmın Peirce'in Göstergebilim Anlayışı Üzerinden Analizi}

\begin{tabular}{cc}
\hline Görüntüsel Gösterge & Liesel’in okulu ve yaşadığı şehir \\
Belirtisel Gösterge & Şehirde NSDAP'nin simgelerinin bulunması, Nazilerin Almanların sosyal \\
Simge & hayatı üzerinde etkisi olduğunu ifade etmektedir \\
\hline
\end{tabular}


Nazi Almanya'sında Nazizm İdeolojisiyle Şekillenen Kitap Okuma Kültürünün Sinemadaki Sunumu: “Kitap Hirsızı" Filminin Göstergebilimsel Analizi

The Presentation of Book Reading Culture Shaped with Nazism Ideology in Nazi Germany in Cinema: The Semiotic Analysis of the Film "The Book Thief"

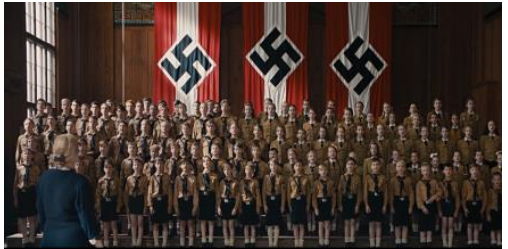

Resim 5. Dördüncü Sekans

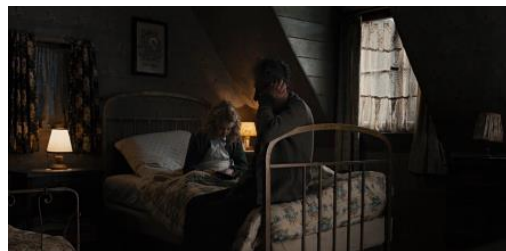

Resim 6. Beşinci Sekans

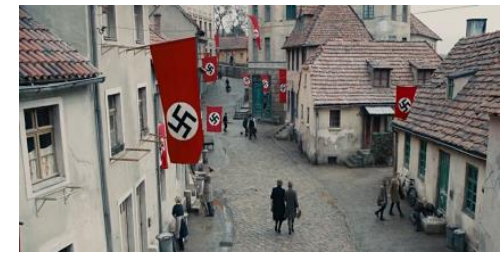

Resim 7. Altınc1 Sekans

Kavramsal anlam boyutunda Almanların sosyal hayatı yansitılmaktadir. HJ üniformaları ve bayraklarından ve Hitler'in doğum günü için asılan Nazi Almanya'sının bayraklarından yan anlamsal anlam açısından Alman sosyal hayatında Nazi rejiminin etkisi aktarılmaktadır. Toplumsal anlam boyutunda NSDAP iktidarında yaşam ortaya konulmaktadır. Partinin, Alman halkının toplumsal hayatı üzerindeki etkisine vurgu yapılmakta, bu açıdan duygusal anlam açısından egemenlik ön plana çıkarılmaktadır. Yansitıcı anlam boyutunda Nazizm, otorite mesajı vermektedir. NSDAP'nin liderliğinde Nazizm ideolojisinin Alman eğitiminde olduğu gibi Alman toplumsal hayatında da egemen olduğu düşüncesi ortaya çıkmaktadır. Eşdizimsel anlam açısından Liesel'in Nazi rejimi altında yaşaması yansıtılmaktadır. Liesel'in eğitim hayatında olduğu gibi toplumsal hayatında da Nazizm ideolojisine maruz kaldığı mesajı verilmektedir. Konusal anlam boyutunda Nazizm ve sosyal hayat vurgulanmaktadır. Nazi Almanya'sında sosyal hayatın Nazizm ideolojisi ekseninde şekillendiğine yönelik algı oluşturulmaktadır.

\section{Tablo 4}

İkinci Kısmın Leech'in Anlamlandırmanın Yedi Türü Üzerinden Analizi

\begin{tabular}{|c|c|c|c|c|c|c|}
\hline $\begin{array}{c}\text { Kavramsal } \\
\text { Anlam }\end{array}$ & $\begin{array}{c}\text { Yan anlamsal } \\
\text { Anlam }\end{array}$ & $\begin{array}{c}\text { Toplumsal } \\
\text { Anlam }\end{array}$ & $\begin{array}{c}\text { Duygusal } \\
\text { Anlam }\end{array}$ & $\begin{array}{c}\text { Yansitıcı } \\
\text { Anlam }\end{array}$ & $\begin{array}{c}\text { Eşdizimsel } \\
\text { Anlam }\end{array}$ & $\begin{array}{c}\text { Konusal } \\
\text { Anlam }\end{array}$ \\
\hline $\begin{array}{c}\text { Almanların } \\
\text { sosyal } \\
\text { hayatı }\end{array}$ & $\begin{array}{l}\text { Alman sosyal } \\
\text { hayatında Nazi } \\
\text { rejiminin etkisi }\end{array}$ & $\begin{array}{c}\text { NSDAP } \\
\text { iktidarında } \\
\text { yaşam }\end{array}$ & Egemenlik & $\begin{array}{c}\text { Nazizm'in } \\
\text { otorite mesaj1 } \\
\text { vermesi }\end{array}$ & $\begin{array}{l}\text { Liesel'in } \\
\text { Nazi rejimi } \\
\text { altında } \\
\text { yaşaması }\end{array}$ & $\begin{array}{l}\text { Nazizm ve } \\
\text { sosyal hayat }\end{array}$ \\
\hline
\end{tabular}

\section{Üçüncü Kısım}

Görüntüsel gösterge boyutunda ele alındığında filmin üçüncü kısmında kitapların yakıldığı meydana yer verildiği görülmektedir. İnsanlar, Nazi rejimi tarafından tehdit olarak sunulan kitapları yakmak için toplanmaktadır (Resim 8). Bu sırada belediye başkanı konuşma yapmaktadır (Resim 9). İlerleyen süreçte kitaplar ateşe verilmektedir (Resim 10). Belirtisel gösterge boyutunda incelendiğinde meydanda NSDAP'nin simgelerinin bulunmasıyla kitapların yakılmasından Nazilerin sorumlu olduğu ortaya çıkmaktadır. Gamalı haçlı bayraklar, Nazi rejimi ve Nazizm ideolojisini simgelemektedir. İnsanların meydanda kitap yakmasının temelinde Nazizm ideolojisi olduğuna vurgu yapılmaktadır. 
Tablo 5

Üçüncü Kısmın Peirce'in Göstergebilim Anlayışı Üzerinden Analizi

\begin{tabular}{cc}
\hline Görüntüsel Gösterge & Kitapların yakıldı̆̆ meydan \\
Belirtisel Gösterge & Meydanda NSDAP'nin simgelerinin bulunması, kitapların yakılmasından \\
& Nazilerin sorumlu olduğunu ifade etmektedir
\end{tabular}

Simge

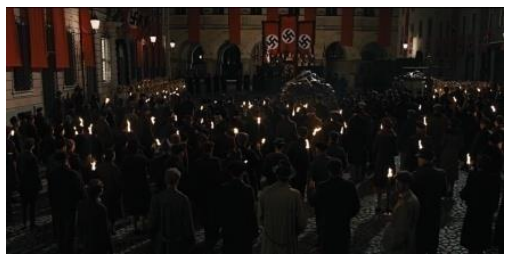

Resim 8. Yedinci Sekans

Gamalı haçlı bayraklar, Nazi rejimi ve Nazizm ideolojisini simgelemektedir

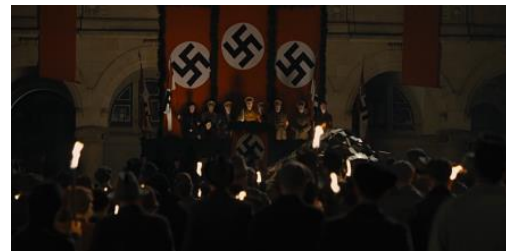

Resim 9. Sekizinci Sekans

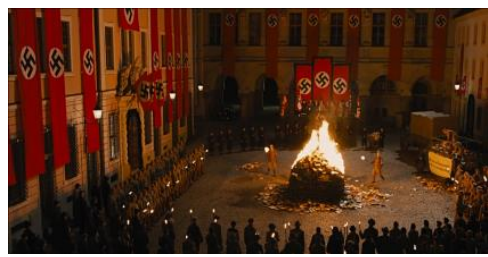

Resim 10. Dokuzuncu Sekans

Kavramsal anlam açısından Almanya'da kitap yakma etkinliği yansıtılmaktadır. Yan anlamsal anlam boyutunda Nazizm ve Nazi rejimi etkisindeki Alman halkı aktarılmaktadır. Filmde yer alan bayraklardan ve üniformalı kişilerden kitap yakma eyleminin Naziler tarafından düzenlendiği mesajı ortaya çıkmaktadır. Bu aşamada toplumsal anlam açısından NSDAP iktidarında inşa edilen düzen ortaya konulmaktadır. Nazi rejimi tarafından tehdit olarak nitelendirilen kitapların yakılması üzerinden duygusal anlam boyutunda öfke ön plana çıkarılmaktadır. Nazilerin, rejimine ve ideolojisine muhalif olan kitaplara yönelik öfke içerisinde olduğu aktarılmaktadır. Yansıtıcı anlam açısından kitapların yakılması, otorite mesaj1 vermektedir. Bu açıdan Nazilerin Alman halkı üzerinde kurduğu otoriteye vurgu yapılmaktadır. Eşdizimsel anlam boyutunda Liesel'in kitaplar konusunda Nazi propagandasına maruz kalması yansıtılmaktadır. Bu açıdan Liesel'in kitaplara yönelik düşüncesinin şekillenmesinde Nazi propagandasına maruz kaldığı aktarılmaktadır. Filmin bu kısmında kitapların yakılması üzerinden konusal anlam açısından Nazizm ve kitaplar vurgulanmaktadır. Bu şekilde Nazizm ideolojisinin Almanya'da hangi kitapların okunup, hangi kitapların okunmayacağı konusunda belirleyici olduğu mesajı verilmektedir.

\section{Tablo 6}

Üçüncü Kısmın Leech'in Anlamlandırmanın Yedi Türü Üzerinden Analizi

\begin{tabular}{ccccccc}
\hline Kavramsal & Yan anlamsal & Toplumsal & Duygusal & Yansıtıcı & Eşdizimsel & Konusal \\
Anlam & Anlam & Anlam & Anlam & Anlam & Anlam & Anlam \\
Almanya'da & Nazizm ve & NSDAP & & Kitapların & Liesel'in kitaplar & \\
kitap yakma & Nazi rejimi & iktidarında & \multirow{2}{*}{ Öfke } & yakılmasının & konusunda Nazi & Nazizm ve \\
etkinliği & etkisindeki & inşa edilen & & otorite mesajı & propagandasına & kitaplar \\
& Alman halkı & düzen & & vermesi & maruz kalması & \\
\hline
\end{tabular}

\section{Dördüncü Kısım}

Görüntüsel gösterge açısından incelendiğinde filmin dördüncü kısmında da kitapların yakıldığg meydana yer verildiği görülmektedir. Meydana toplanan halk, kitaplar yanarken Das Lied der Deutschen'1 söylemektedir (Resim 11). Diğer yandan Liesel'in de kitap yakmas1 istenmekte (Resim 12) ve Liesel de bir kitabı ateşe atmaktadır (Resim 13). Belirtisel gösterge 
Nazi Almanya'sında Nazizm İdeolojisiyle Şekillenen Kitap Okuma Kültürünün Sinemadaki Sunumu: “Kitap Hirsızı" Filminin Göstergebilimsel Analizi

The Presentation of Book Reading Culture Shaped with Nazism Ideology in Nazi Germany in Cinema: The Semiotic Analysis of the Film "The Book Thief"

üzerinden ele alındığında Nazi Selamı ve Nazi Almanya'sının milli marşı Das Lied der Deutschen'in söylenmesi, kitap yakma eyleminin ulusal bir görevmiş gibi algılanmasına yol açmaktadır. Nazi selamı, Nazi rejimi ve Nazizm ideolojisini simgelemektedir. Tüm bu süreçte Nazi rejimine muhalif kitapların yakılması, insanların Nazi Almanya'sına bağl1lıklarının bir göstergesi olarak sunulmaktadır.

\section{Tablo 7}

Dördüncü Kısmın Peirce'in Göstergebilim Anlayışı Üzerinden Analizi

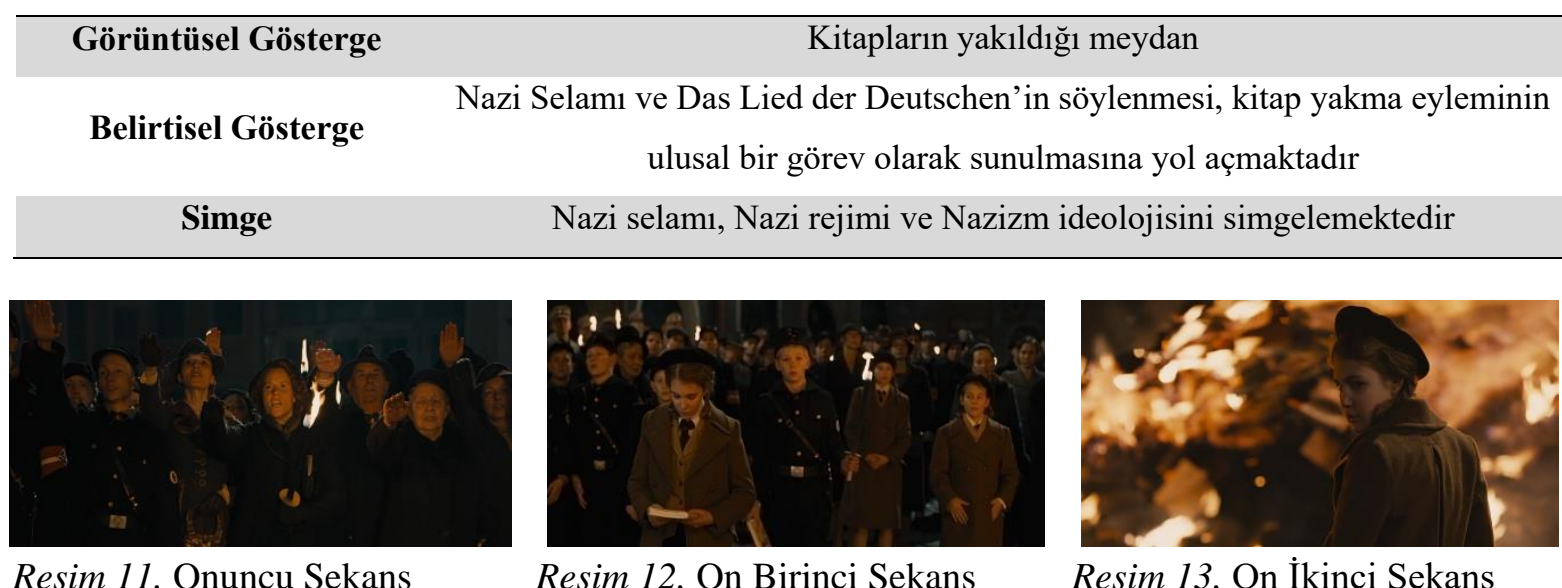

Kavramsal anlam boyutunda Almanya'da kitap yakma etkinliği yansitılmaktadır. Yan anlamsal anlam açısından Nazi rejiminin Alman halkı üzerinde kurduğu kontrol aktarılmaktadır. Nazi selamı verilmesi ve aynı zamanda dönemin Alman milli marşının söylemesi, kitap yakma etkinliğinin Nazilerce düzenlendiği mesajını vermektedir. Toplumsal anlam boyutunda NSDAP iktidarında otorite ortaya konulmaktadır. NSDAP'nin Alman halk1 üzerinde kurduğu otorite aracılığıyla da duygusal anlam açısından egemenlik ön plana çıkarılmaktadır. NSDAP'nin Alman sosyal hayatına egemen olduğu ve insanların okudukları kitaplar üzerinde bile etki oluşturabildiği algısı meydana getirilmektedir. Yansıtıcı anlam boyutunda kitapların yakılması, baskı mesajı vermektedir. Nitekim eşdizimsel anlam açısından Liesel'in kitap yakmaya zorlanması yansıtılmaktadır. Liesel'in kitap yakmaya zorlanması, Nazi rejiminin insanlar üzerinde bask1 oluşturduğuna yönelik algının meydana gelmesine yol açmaktadır. Kitap yakma etkinliği üzerinden de konusal anlam boyutunda Nazizm ve kitaplar vurgulanmaktadır.

\section{Tablo 8}

Dördüncü Kısmın Leech 'in Anlamlandırmanın Yedi Türü Üzerinden Analizi

\begin{tabular}{|c|c|c|c|c|c|c|}
\hline $\begin{array}{c}\text { Kavramsal } \\
\text { Anlam }\end{array}$ & $\begin{array}{c}\text { Yan anlamsal } \\
\text { Anlam }\end{array}$ & $\begin{array}{c}\text { Toplumsal } \\
\text { Anlam }\end{array}$ & $\begin{array}{c}\text { Duygusal } \\
\text { Anlam }\end{array}$ & $\begin{array}{l}\text { Yansitici } \\
\text { Anlam }\end{array}$ & $\begin{array}{c}\text { Eşdizimsel } \\
\text { Anlam }\end{array}$ & $\begin{array}{c}\text { Konusal } \\
\text { Anlam }\end{array}$ \\
\hline $\begin{array}{l}\text { Almanya'da } \\
\text { kitap yakma } \\
\text { etkinliği }\end{array}$ & $\begin{array}{l}\text { Nazi rejiminin } \\
\text { Alman halkı } \\
\text { üzerinde } \\
\text { kurduğu } \\
\text { kontrol }\end{array}$ & $\begin{array}{l}\text { NSDAP } \\
\text { iktidarında } \\
\text { otorite }\end{array}$ & Egemenlik & $\begin{array}{c}\text { Kitapların } \\
\text { yakılmasının } \\
\text { baskı mesajı } \\
\text { vermesi }\end{array}$ & $\begin{array}{l}\text { Liesel'in } \\
\text { kitap } \\
\text { yakmaya } \\
\text { zorlanması }\end{array}$ & $\begin{array}{c}\text { Nazizm ve } \\
\text { kitaplar }\end{array}$ \\
\hline
\end{tabular}




\section{Beşinci Klsım}

Görüntüsel gösterge boyutunda ele alındığında filmin beşinci kısmında yine kitapların yakıldığı meydana yer verildiği görülmektedir. Kitap yakma etkinliği sona erdikten sonra Liesel meydana gelmekte ve yanmakta olan kitap yığınından bir kitabı almaktadır (Resim 14). Liesel'in kitabı aldığını belediye başkanının eşi Ilsa Hermann görmektedir (Resim 15). Bu sırada Liesel'in koruyucu babası Liesel'i almaya gelmektedir (Resim 16). Belirtisel gösterge boyutunda incelendiğinde Liesel'in kitabı alması, Nazi rejiminin kitaplar konusundaki fikrine katılmadığı algısını meydana getirmektedir. Yanmış kitaplar, muhalefeti simgelemekte ve Nazilerce tehdit olarak yansitılmaktadır.

Tablo 9

Beşinci Kısmın Peirce'in Göstergebilim Anlayışı Üzerinden Analizi

\begin{tabular}{|c|c|}
\hline Görüntüsel Gösterge & Kitapların yakıldığı meydan \\
\hline Belirtisel Gösterge & $\begin{array}{l}\text { Liesel'in kitabı alması, Nazi rejiminin kitaplar konusundaki fikrine } \\
\text { katılmadığını ifade etmektedir }\end{array}$ \\
\hline Simge & Yanmış kitaplar, muhalefeti simgelemektedir \\
\hline 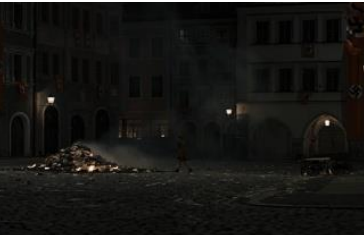 & 8 \\
\hline
\end{tabular}

Kavramsal anlam açısından Almanya'da kitap yakma etkinliği sonrası yansıtılmaktadır. Liesel'in yanmakta olan kitaplar içerisinden bir kitabı almasıyla yan anlamsal anlam boyutunda Nazi rejimi tarafından oluşturulan düzene karşıtlık aktarılmaktadır. Toplumsal anlam açısından NSDAP iktidarında otorite ortaya konulmaktadır. Buna karşılık Liesel'in hareketi üzerinden duygusal anlam boyutunda karşıtlık ön plana çıkarılmaktadır. Yansıtıcı anlam açısından kitabın alınması, sorgulama mesajı vermektedir. Liesel'in kitabı alması Nazi rejimini ve Nazizm ideolojisini sorguladığı düşüncesinin oluşmasına neden olmaktadır. Eşdizimsel anlam boyutunda Liesel'in Nazi rejiminin kitap politikasına karşı hareket etmesi yansıtılmaktadır. Kitap yakma etkinliği üzerinde de yine konusal anlam açısından Nazizm ve kitaplar vurgulanmaktadır.

Tablo 10

Beşinci Klsmın Leech'in Anlamlandırmanın Yedi Türü Üzerinden Analizi

\begin{tabular}{ccccccc}
\hline Kavramsal & Yan anlamsal & Toplumsal & Duygusal & Yansıtıcı & Eşdizimsel & Konusal \\
Anlam & Anlam & Anlam & Anlam & Anlam & Anlam & Anlam \\
Almanya'da & Nazi rejimi & & & Kitabın & Liesel’in Nazi & \\
kitap yakma & tarafından & NSDAP & & alınmasının & rejiminin kitap & Nazizm ve \\
etkinliği & oluşturulan & iktidarında & Karşıtlık & sorgulama & politikasına & kitaplar \\
sonrası & düzene & otorite & & mesajı & karşı hareket & \\
& karşıtlık & & & vermesi & etmesi & \\
\hline
\end{tabular}


Nazi Almanya'sında Nazizm İdeolojisiyle Şekillenen Kitap Okuma Kültürünün Sinemadaki Sunumu: “Kitap Hirsızı" Filminin Göstergebilimsel Analizi

The Presentation of Book Reading Culture Shaped with Nazism Ideology in Nazi Germany in Cinema: The Semiotic Analysis of the Film "The Book Thief"

\section{Altıncı Klsım}

Görüntüsel gösterge açısından incelendiğinde filmin altıncı kısmında Liesel'in koruyucu ailesinin ve belediye başkanının evlerine yer verildiği görülmektedir. Liesel, evde kitap okumayı sürdürmektedir (Resim 17). Bu sırada Liesel'in evlerinde Nazilerden saklanan bir Yahudi bulunmaktadır (Resim 18). Yanan kitaplar içerisinden Liesel'in kitap aldığını gören Hermann, Liesel'i evde bulunan kütüphaneye davet etmektedir (Resim 19). Belirtisel gösterge üzerinden ele alındığında Liesel'in kitap okuması, Liesel'in kitap okuma ilgisini yansıtmaktadır. Bu aşamada kitaplar da öğrenmeyi simgelemektedir.

\section{Tablo 11}

Altıncı Kısmın Peirce'in Göstergebilim Anlayışı Üzerinden Analizi

\begin{tabular}{cc}
\hline $\begin{array}{c}\text { Görüntüsel Gösterge } \\
\text { Belirtisel Gösterge } \\
\text { Simge }\end{array}$ & $\begin{array}{c}\text { Liesel'in koruyucu ailesinin ve belediye başkanının evleri } \\
\text { Liesel'in kitap okuması, Liesel'in kitap okuma ilgisini yansıtmaktadır } \\
\text { Kitaplar, öğrenmeyi simgelemektedir }\end{array}$ \\
\hline
\end{tabular}

Resim 17. On Altınc1 Sekans

Resim 18. On Yedinci Sekans

Resim 19. On Sekizinci Sekans

Kavramsal anlam boyutunda Liesel'in çevresindeki insanlarla geçirdiği zaman yansıtılmaktadır. Bu aşamada Liesel'in kitaplara ilgisiyle yan anlamsal anlam açısından kitap okuma sevgisi aktarılmaktadır. Toplumsal anlam boyutunda NSDAP iktidarında yaşam ortaya konulmaktadır. Liesel'in kitaplara sevgisi vurgulanmakta, bu açıdan duygusal anlam açısından sevgi ön plana çıkarılmaktadır. Yansıtıcı anlam boyutunda da Liesel'in kitap okuması, kitap okuma sevgisini aktarmaktadır. Eşdizimsel anlam açısından Liesel'in kitap okumayı hayatının bir parçası haline getirmesi yansıtılmaktadır. Bu aşamada da konusal anlam boyutunda kitap okuma vurgulanmaktadır.

Tablo 12

Altıncı Kısmın Leech 'in Anlamlandırmanın Yedi Türü Üzerinden Analizi

\begin{tabular}{|c|c|c|c|c|c|c|}
\hline $\begin{array}{c}\text { Kavramsal } \\
\text { Anlam }\end{array}$ & $\begin{array}{c}\text { Yan anlamsal } \\
\text { Anlam }\end{array}$ & $\begin{array}{c}\text { Toplumsal } \\
\text { Anlam }\end{array}$ & $\begin{array}{c}\text { Duygusal } \\
\text { Anlam }\end{array}$ & $\begin{array}{c}\text { Yansiticı } \\
\text { Anlam }\end{array}$ & $\begin{array}{c}\text { Eşdizimsel } \\
\text { Anlam }\end{array}$ & $\begin{array}{c}\text { Konusal } \\
\text { Anlam }\end{array}$ \\
\hline $\begin{array}{c}\text { Liesel'in } \\
\text { çevresindeki } \\
\text { insanlarla } \\
\text { geçirdiği } \\
\text { zaman }\end{array}$ & $\begin{array}{c}\text { Kitap okuma } \\
\text { sevgisi }\end{array}$ & $\begin{array}{c}\text { NSDAP } \\
\text { iktidarında } \\
\text { yaşam }\end{array}$ & Sevgi & $\begin{array}{c}\text { Liesel'in kitap } \\
\text { okumasının } \\
\text { kitap okuma } \\
\text { sevgisini } \\
\text { aktarması }\end{array}$ & $\begin{array}{l}\text { Liesel'in kitap } \\
\text { okumayı } \\
\text { hayatının bir } \\
\text { parçası haline } \\
\text { getirmesi }\end{array}$ & $\begin{array}{l}\text { Kitap } \\
\text { okuma }\end{array}$ \\
\hline
\end{tabular}




\section{Yedinci Klsim}

Görüntüsel gösterge boyutunda ele alındığında filmin yedinci kısmında Liesel'in koruyucu ailesinin evine yer verildiği görülmektedir. Liesel'in evinde saklanan Yahudi Max Vandenburg, Kavgam kitabının sayfalarını ve kitapta bulunan Hitler'in fotoğrafını beyaza boyamaktadır (Resim 20). Daha sonra sayfaları boyanan kitabı Liesel'e hediye etmektedir (Resim 21). Sayfaları Liesel'in doldurmasını istemektedir. Liesel de Vandenburg'a kitap okumaktadır (Resim 22). Belirtisel gösterge boyutunda incelendiğinde Kavgam kitabının boyanması, Nazi rejiminin öğretilerine karşı çıkılmasını ifade etmektedir. Kitabın boş sayfalarının Liesel tarafından doldurulmasıyla kitapla yaşam arasında bir ilişki meydana gelmektedir. Bu açıdan kitap, yaşamı simgelemektedir.

\section{Tablo 13}

Yedinci Kısmın Peirce'in Göstergebilim Anlayışı Üzerinden Analizi

\begin{tabular}{cc}
\hline Görüntüsel Gösterge & Liesel’in koruyucu ailesinin evi \\
Belirtisel Gösterge & Kavgam kitabının boyanması, Nazi rejiminin öğretilerine karşı çıkılmasını \\
Simge & ifade etmektedir \\
\hline
\end{tabular}
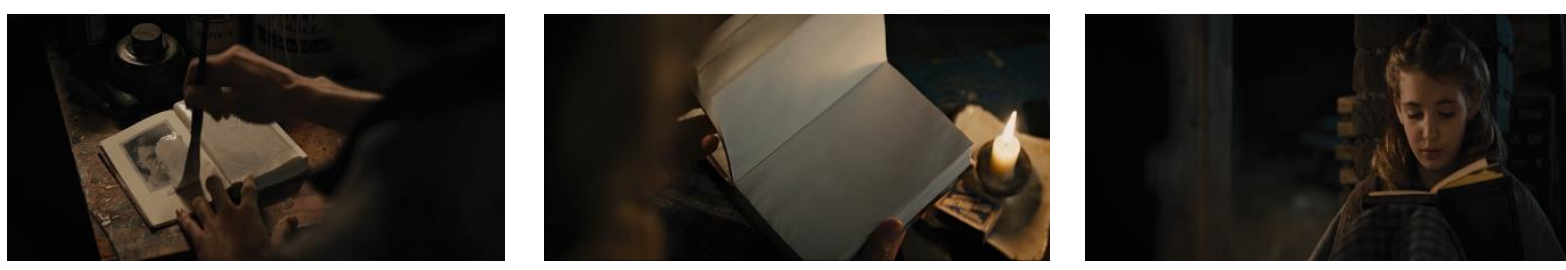

Resim 20. On Dokuzuncu Sekans Resim 21. Yirminci Sekans

Resim 22. Yirmi Birinci Sekans

Kavramsal anlam açısından Liesel ve Vandenburg yansitılmaktadır. Liesel'e kitap hediye edilmesi ve Liesel'in kitap okuması üzerinden yan anlamsal anlam boyutunda kitap okuma sevgisi aktarılmaktadır. Toplumsal anlam açısından NSDAP iktidarında yaşam ortaya konulmaktadır. Liesel'in kitaplara olan ilgisinden dolayı duygusal anlam boyutunda sevgi ön plana çıkarılmaktadır. Yansitıcı anlam boyutunda da Liesel'in kitap okuması, kitap okuma sevgisini aktarmaktadır. Eşdizimsel anlam boyutunda Liesel'in kitap okuma isteği yansıtılmaktadır. Konusal anlam açısından da kitap okuma vurgulanmaktadır.

\section{Tablo 14}

Yedinci Kısmın Leech'in Anlamlandırmanın Yedi Türü Üzerinden Analizi

\begin{tabular}{ccccccc}
\hline Kavramsal & Yan anlamsal & Toplumsal & Duygusal & Yansitıcı & Eşdizimsel & Konusal \\
Anlam & Anlam & Anlam & Anlam & Anlam & Anlam & Anlam \\
Liesel ve & Kitap okuma & NSDAP & & Liesel'in kitap & \\
Vandenburg & sevgisi & iktidarında & Sevgi & kitap okuma & kitap okuma & Kitap okuma \\
& & yaşam & & sevgisini & isteği & \\
& & & & aktarmasi & & \\
\hline
\end{tabular}


Nazi Almanya'sında Nazizm İdeolojisiyle Şekillenen Kitap Okuma Kültürünün Sinemadaki Sunumu: “Kitap Hirsızı" Filminin Göstergebilimsel Analizi

The Presentation of Book Reading Culture Shaped with Nazism Ideology in Nazi Germany in Cinema: The Semiotic Analysis of the Film "The Book Thief"

\section{Sekizinci Klsım}

Görüntüsel gösterge açısından incelendiğinde filmin sekizinci kısmında belediye başkanının evine yer verildiği görülmektedir. Liesel, belediye başkanının evine gizlice girerek, evdeki kütüphaneden izinsiz kitap almaktadır (Resim 23). İlerleyen süreçte Liesel tekrar izinsiz kitap almakta (Resim 24) ve bu sırada arkadaşı Rudy'e yakalanmaktadır (Resim 25). Belirtisel gösterge üzerinden ele alındığında Liesel'in kitapları izinsiz almasıyla, Liesel'in kitap okuma isteğinin önlenememesi ifade edilmektedir. Bu aşamada kitaplar, bağımlılığı simgelemektedir.

\section{Tablo 15}

Sekizinci Kısmın Peirce'in Göstergebilim Anlayışı Üzerinden Analizi

\begin{tabular}{cc}
\hline Görüntüsel Gösterge & Belediye başkanının evi \\
Belirtisel Gösterge & Liesel'in kitapları izinsiz almasıly, Liesel'in kitap okuma isteğinin \\
Simge & önlenememesi ifade edilmektedir \\
\hline & Kitaplar, bağımlılığı simgelemektedir \\
\hline &
\end{tabular}

Kavramsal anlam boyutunda Liesel'in gizlice kitap alması yansitılmaktadır. Liesel'in gizlice kitap alması üzerinden yan anlamsal anlam açısından kitap okuma isteği aktarılmaktadır. Toplumsal anlam boyutunda da yine NSDAP iktidarında yaşam ortaya konulmaktadır. Liesel'in izinsiz olarak kitap almasından dolayı duygusal anlam açısından korku ön plana çıkarılmaktadır. Yansıtıcı anlam boyutunda kitabın alınması, kitap okuma isteğini aktarmaktadır. Eşdizimsel anlam açısından Liesel'in kitap okuma çabası yansitılmaktadır. Konusal anlam boyutunda da kitap okuma vurgulanmaktadır.

\section{Tablo 16}

Sekizinci Kısmın Leech 'in Anlamlandırmanın Yedi Türü Üzerinden Analizi

\begin{tabular}{ccccccc}
\hline Kavramsal & Yan anlamsal & Toplumsal & Duygusal & Yansıtıcı & Eşdizimsel & Konusal \\
Anlam & Anlam & Anlam & Anlam & Anlam & Anlam & Anlam \\
Liesel'in & Kitap okuma & NSDAP & & Kitabın & \\
gizlice kitap & isteği & iktidarında & Korku & kitap okuma & kitap okuma & Kitap okuma \\
alması & & yaşam & & isteğini & çabası & \\
& & & aktarması & & \\
\hline
\end{tabular}




\section{Dokuzuncu Klsım}

Görüntüsel gösterge boyutunda ele alındığında filmin dokuzuncu ve çalışma kapsamında incelenen son kısminda Liesel'in koruyucu ailesinin bulunduğu sokağa yer verildiği görülmektedir. Liesel'in kaldığı ev bir hava bombardımanına hedef olmuş ve Liesel, hava bombardımanı sırasında koruyucu ailesini kaybetmiştir (Resim 26). Bu sırada Liesel yıkıntılar arasında kitabını bulmuştur (Resim 27). Liesel'in yanına Hermann gelmiş ve ona sarılmıştır (Resim 28). Belirtisel gösterge boyutunda incelendiğinde Liesel'in y1kıntılar içerisinden kitab1 alması, Liesel'in geçmişini korumaya çalıştığını ifade etmektedir. Bu aşamada kitap, geçmişi simgelemektedir.

\section{Tablo 17}

Dokuzuncu Kısmın Peirce'in Göstergebilim Anlayışı Üzerinden Analizi

\begin{tabular}{cc}
\hline Görüntüsel Gösterge & Liesel'in koruyucu ailesinin bulunduğu sokak \\
Belirtisel Gösterge & Liesel'in yıkıntılar içerisinden kitabı alması, Liesel'in geçmişini korumaya \\
Simge & çalıştığını ifade etmektedir \\
Kitap, geçmişi simgelemektedir \\
\hline
\end{tabular}

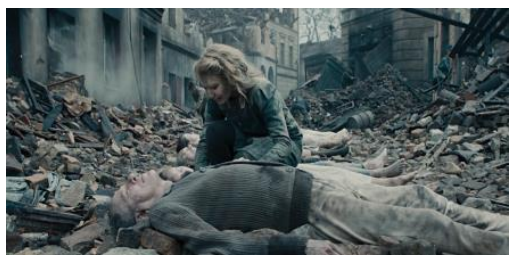

Resim 26. Yirmi Beşinci Sekans

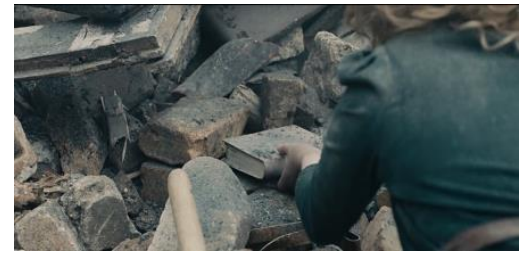

Resim 27. Yirmi Altıncı Sekans

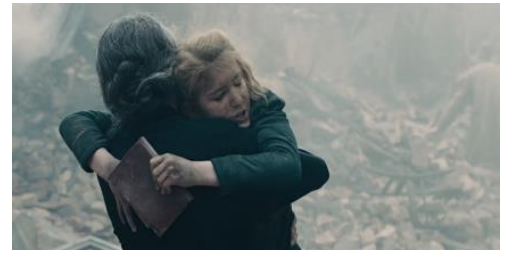

Resim 28. Yirmi Yedinci Sekans

Kavramsal anlam açısından Liesel'in bulunduğu sokağın hava bombardımanından sonraki hali yansıtılmaktadır. Liesel'in yıkıntılar içerisinden kitabı almasıyla yan anlamsal anlam boyutunda geçmişe dair kitabın kalması aktarılmaktadır. Toplumsal anlam açısından İkinci Dünya Savaşı'nda Almanya'ya yönelik hava bombardımanı ortaya konulmaktadır. Hava bombardımanı sonucunda insanların hayatlarını kaybetmesiyle duygusal anlam boyutunda hüzün ön plana çıkarılmaktadır. Yansıtıcı anlam açısından da kitabın tutulması, kitap sevgisini aktarmaktadır. Eşdizimsel anlam boyutunda Liesel'in zor anlarında bile kitabını bırakmaması yansıtılmaktadır. Geçmişe dair kitabın kalmasıyla konusal anlam açısından geçmiş ve kitap vurgulanmaktadır.

Tablo 18

Dokuzuncu Kısmın Leech'in Anlamlandırmanın Yedi Türü Üzerinden Analizi

\begin{tabular}{ccccccc}
\hline Kavramsal & Yan anlamsal & Toplumsal & Duygusal & Yansıtıcı & Eşdizimsel & Konusal \\
Anlam & Anlam & Anlam & Anlam & Anlam & Anlam & Anlam \\
Liesel'in & & İkinci Dünya & & Kitabın & Liesel'in zor & \\
bulunduğu sokağın & Geçmişe dair & Savaşı'nda & & tutulmasının & anlarında & Geçmiş ve \\
hava & kitabın & Almanya'ya & Hüzün & kitap & bile kitabını & kitap \\
bombardımanından & kalması & yönelik hava & & sevgisini & birakmaması & \\
bonraki hali & & bombardımanı & & aktarması & & \\
\hline
\end{tabular}


Nazi Almanya'sında Nazizm İdeolojisiyle Şekillenen Kitap Okuma Kültürünün Sinemadaki Sunumu: “Kitap Hirsızı" Filminin Göstergebilimsel Analizi

The Presentation of Book Reading Culture Shaped with Nazism Ideology in Nazi Germany in Cinema: The Semiotic Analysis of the Film "The Book Thief"

\section{Sonuç}

Çalışmada incelenen Kitap Hırsızı filminde, Nazi Almanya'sında Nazizm ideolojisinin Alman halkının sosyal hayatında önemli bir etkiye sahip olduğu yansıtılmıştır. Filmde Nazi rejiminin Alman eğitimi üzerindeki etkisi vurgulanarak, Alman öğrencilerin doğrudan Nazi propagandasına maruz kaldığına yönelik algı oluşturulmuştur. Diğer yandan Nazizm ideolojisinin öğretilerinin Alman eğitiminde ön plana çıkarıldığı vurgulanarak, Nazi Almanya'sında ideolojinin eğitime ne şekilde yansıtıldığı ortaya konulmuştur. Filmde özellikle ülkede muhalif kitapların ortadan kaldırılarak, Alman halkının kitaplar üzerinden Nazizm ideolojisinin öğretilerine karşıt her türlü düşünceye ulaşmasının engellenmesine çalışıldığına vurgu yapılmıştır.

Liesel'in başından geçen olaylar üzerinden filmde kitap okuma kültürünün şekillenmesinde Nazizm ideolojisinin önemli bir rolü olduğuna yönelik algı oluşmaktadır. Filmdeki kurguda Nazi Almanya'sında Liesel istediği her kitabı okuyamamakta, okuyacağı kitaplar doğrudan Nazi rejimi tarafından sınırlandırılmaktadır. Diğer bir deyişle filmde Naziler, Liesel'in hangi kitapları okuyabileceğini belirlemekte ve Nazi rejimi ve Nazizm ideolojisine muhalif olan ya da tehdit oluşturabilecek kitapların okunması engellenmektedir. $\mathrm{Bu}$ aşamada filmde Nazilerin muhalif kitapların ortadan kaldırılması için düzenlenen kitap yakma etkinliği, Nazilerin iktidarını toplum nezdinde güçlendirilmesinin bir yolu olarak algılanabilmektedir. Nitekim filmin kurgusunda kitapların yakılmasıyla, Nazizm ideolojisinin dışındaki farklı söylemlerin benimsenmesinin engellenmeye çalışıldığı düşüncesi meydana gelmektedir. $\mathrm{Bu}$ şekilde filmde kitlelerin Nazizm ideolojisini benimseyen ve Nazilerce idealize edilen vatandaşlar olmasına çalışıldığı ortaya konulmuştur.

İnsanların düşüncelerinin şekillenmesinde, hayata yönelik bakış açıları oluşturmasında ve kimi zaman da belirli bir fikri, düşünceyi veya ideolojiyi benimsemesinde kitaplar önemli rol oynayabilmektedir. Bu açıdan egemen güçler, kitlelerin düşüncelerinin istenilen yönde şekillenmesini sağlayabilmek için insanların okudukları kitaplara doğrudan müdahale edebilmektedir. Filmde Liesel'in yaşadığı olaylar yoluyla Alman halkının kitap okuma kültüründe Nazi rejiminin güçlü bir etkisinin olduğu kurgulanmıştır. Filmdeki görsel ve sözlü göstergeler üzerinden Nazilerin, ülkede elde ettiği güçlü otoriteden yararlanarak Alman halkının kitap okuma kültürünü istediği yönde şekillendirmeye çalıştığına yönelik alg1 meydana gelmiştir.

Filmde egemen gücün düşüncelerini kitlelere benimsetmesi sürecinde kitaplardan ne yönde yararlandığına yönelik kurgu oluşturulmuştur. $\mathrm{Bu}$ aşamada film üzerinden egemen gücün, söylemlerini kitlelere benimsetmesinde kitapları bir araç olarak değerlendirdiği algısı meydana gelmektedir. Fimdeki kurguda egemen güç, kendi düşüncelerine karşı olan yayınları ortadan kaldırarak, ülkede kendi ideolojisini hakim kılmaya çalışığı mesajı verilmektedir. Tüm bu süreçte film üzerinden egemen gücün dilinin, toplum tarafindan benimsenmesinde kültürel faaliyetlerin önem taşıdığına yönelik düşünce ortaya çıkarılmaktadır.

Genel olarak değerlendirildiğinde film üzerinden kitapların yakılmasıyla Nazi rejiminin, Nazi Almanya'sında insanların kitap okuma kültürünün özgür biçimde şekillenmesini engellemeye çalıştığının kurgulandığı ortaya çıkmaktadır. $\mathrm{Bu}$ aşamada 
Liesel'in kitap yakma etkinliğinden sonra yanan kitaplar içerisinden gizlice kitap alması, filmde Liesel'in kitap okuma kültürünü özgürce şekillendirme çabası olarak yansıtılmaktadır. Ayrıca filmde Liesel'in yaşadığı tüm zorluklara rağmen kitap okumayı bırakmadığı mesajı verilmektedir. Filmde toplumsal bask1 sonucunda muhalif kitapların okunmasının engellediğine yönelik algı oluşturulmaktadır. Diğer bir deyişle filmde Nazi Almanya'sında Alman halkının kitap okuma kültürünü özgürce şekillendirmesinde toplumsal baskının önemli bir engel olarak sunulduğu ileri sürülebilmektedir. Bu süreçte filmde Liesel'in yaşadığ1 zorluklar üzerinden Nazi Almanya'sında kitap okuma kültürünün özgürce şekillenmesinin ne kadar güç olduğuna yönelik algı meydana gelmektedir. Tüm bu aşamada film üzerinden kitap okuma kültürünün şekillenmesinde özgür bir ortamın ne kadar önem taşıdığı düşüncesi ortaya çıkabilmektedir. Filmde elde edilen bulgular, filmdeki kurgunun göstergebilimsel bir analizini yansıtmaktadır. Bu açıdan çalışmadaki bulgular üzerinden Nazi Almanya'sında kitap okuma kültürünün ne yönde şekillendiğine ilişkin genellemede bulunulmamaktadır. Gelecek çalışmalarda kitapların konu edildiği 2008 yapımı Kırık Kalp Kütüphanesi (Heartbreak Library) ya da 2017 yapımı Sahaf (The Bookshop) gibi filmlerin kitap okuma boyutunda incelenmesiyle sinema ve kitap bağlantılı literatüre katkı sağlanması mümkün olabilecektir.

\section{Kaynakça}

Akindele, N. (2012). Reading culture, parental involvement and children's development in formative years: The Covenant University Experience. Library Philosophy and Practice (e-journal), 1-21.

Ascheid, A. (2010). Hitler's heroines: Stardom \& womanhood in Nazi cinema. The United States: Temple University Press.

Azmi, M. N. L. (2013). National language policy and its impacts on second language reading culture. Journal of International Education and Leadership, 3(1), 1-11.

Barthes, R. (2015). Bir deneme bir ders: Eiffel Kulesi ve açıllı̧ dersi. (M. Rifat, S. Rifat, Çev.). 2. bask1. İstanbul: Yap1 Kredi Yayınları.

Berman, A. (1992). Nazism, the Jews and American Zionism, 1933-1988. The United States: Wayne State University Press.

Buchanan, R. (2012). Zines in the classroom: Reading culture. English Journal, 102(2), 71-77.

Campbell, B. (2004). The SA generals and the rise of Nazism. The United States: University Press of Kentucky.

Collingwood, R. G. (1940). Fascism and Nazism. Philosophy, 15(58), 168-176.

Çakı, C., Gazi, M. A., Çakı, G. ve Gülada, M. O. (2020). Likbez Kampanyası dönemindeki propaganda posterleri üzerine göstergebilimsel bir inceleme. Türk Kütüphaneciliği, 34(4), 663692. doi: 10.24146/tk.806892.

Daniels, E. ve Steres, M. (2011). Examining the effects of a school-wide reading culture on the engagement of middle school students. RMLE Online, 35(2), 1-13. doi: 10.1080/19404476.2011.11462085

Davidson, E. (1997). The making of Adolf Hitler: The birth and rise of Nazism. The United States: University of Missouri Press.

Dick, A. L. (2006). Book history, library history and South Africa's reading culture. South African Historical Journal, 55(1), 33-45. doi: 10.1080/02582470609464929

Dunlop, J. B. (1996). Alexander Barkashov and the rise of National Socialism in Russia. Demokratizatsiya, 4(4), 519-30. 
Nazi Almanya’sında Nazizm İdeolojisiyle Şekillenen Kitap Okuma Kültürünün Sinemadaki Sunumu: “Kitap Hırsızı" Filminin Göstergebilimsel Analizi

The Presentation of Book Reading Culture Shaped with Nazism Ideology in Nazi Germany in Cinema: The Semiotic Analysis of the Film "The Book Thief"

Dülffer, J. (1976). Bonapartism, Fascism and National Socialism. Journal of Contemporary History, 11(4), 109-128. doi: 10.1177/002200947601100407

Egong, A. I. (2014). Reading culture and academic achievement among secondary school students. Journal of Education and Practice, 5(3), 132-136.

Eley, G. (2013). Nazism as Fascism: violence, ideology, and the ground of consent in Germany 19301945. The United Kingdom: Routledge.

Erol, E. (2020). The publishing in Nazi Germany, the construction of anti-semitist discourses spread by the Nazism Ideology and the use of books for the purpose of propaganda. Turkish Librarianship, 34(4), 693-722. doi: 10.24146/tk.818460

Fabunmi, F. A., ve Folorunso, O. (2010). Poor reading culture: A barrier to students' patronage of libraries selected secondary school in ado local government area of Ekiti-State, Nigeria. African Research Review, 4(2), 450-461. doi: 10.4314/afrrev.v4i2.58357

Falter, J. W. (2014). Political cleavages in the Weimar republic and the rise of National Socialism. European Political Science, 13, 106-116. doi: 10.1057/eps.2013.41

Farias, V. (1989). Heidegger and Nazism. The United States: Temple University Press.

Fischer, C. (1991). The German communists and the rise of Nazism. Germany: Springer.

Fiske, J. (2017). İletişim çalışmalarına giriş. (S. İrvan, Çev.). 5. bs. Ankara: Bilim ve Sanat Yayınları.

Forti, S. (2006). The biopolitics of souls: Racism, Nazism, and Plato. Political Theory, 34(1), 9-32. doi: $10.1177 / 0090591705280526$

Frosh, S. (2015). Hate and the 'Jewish science': anti-semitism, Nazism and psychoanalysis. Germany: Springer.

Gazi, M. A., Çakı, C., Gülada, M. O. ve Çakı, G. (2020). Çin Halk Cumhuriyeti Kültür Devrimi sürecinde okuma alışkanlığının propaganda posterlerinde sunumu. Türk Kütüphaneciliği, 34(3), 406-431. doi: 10.24146/tk.806892

Geary, R. (2002). Hitler and Nazism. The United Kingdom: Routledge.

Geyer, M. ve Fitzpatrick, S. (2009). Beyond totalitarianism: Stalinism and Nazism compared. The United Kingdon: Cambridge University Press.

Giles, G. J. (2014). Students and National Socialism in Germany. The United States: Princeton University Press.

Goodrick-Clarke, N. (1993). The occult roots of Nazism: Secret aryan cults and their influence on Nazi Ideology. New York: NYU Press.

Häberlen, J. C. (2013). Scope for agency and political options. The German working-class movement and the rise of Nazism. Politics, Religion \& Ideology, 14(3), 377-394. doi: $10.1080 / 21567689.2013 .820443$

Hake, S. (2010). Popular cinema of the Third Reich. The United States: University of Texas Press.

Hamilton, R. F. (2003). The rise of Nazism: A case study and review of interpretations: Kiel, 19281933. German Studies Review, 26(1), 43-62. doi: 10.2307/1432901

Hansen, E. (1981). Fascism and Nazism in the Netherlands 1929-39. European Studies Review, 11(3), 355-385. doi: 10.1177/026569148101100304

Harsch, D. (1993). German social democracy and the rise of Nazism. The United States: Univ of North Carolina Press.

Hart, B. L. (2015). İkinci Dünya Savaşı tarihi. (K. Bağrıaçı, Çev.). İstanbul: İş Bankası Yayınları. 
Heidtmann, H. (2002). Lesen und neue Medien. Veränderungen der Lesekultur in der Mediengesellschaft. Universitas (Stuttgart), 57(673), 723-732.

Herf, J. (1993). Multiple restorations: German political traditions and the interpretation of Nazism, 1945-1946. Central European History, 26(1), 21-55.

Herkommer, C. (2008). Women under National Socialism: Women's scope for action and the issue of gender. O. Jensen ve C.-C. W. Szejnmann (Ed.), in Ordinary people as mass murderers (s. 99119). London: Palgrave Macmillan. doi: 10.1057/9780230583566_5

Herman, F. (2001). Hollywood, Nazism, and the Jews, 1933-41. American Jewish History, 89(1), 6189.

Hochscherf, T., ve Vande Winkel, R. (2016). Third Reich cinema and film theory. Historical Journal of Film, Radio and Television, 36(2), 190-213. doi: 10.1080/01439685.2016.1167465

Howley, J. A. (2018). Aulus Gellius and Roman reading culture. The United Kingdom: Cambridge University Press.

Hull, D. S. (1993). Film in the Third Reich: A study of the German cinema, 1933-1945. The United States: University of California Press.

Ian, K. (1997). Stalinism and Nazism: Dictatorships in comparison. Cambridge University Press.

Ifedili, C. J. A. (2009). An assessment of reading culture among students in Nigerian tertiary institution--a challenge to educational managers. Reading Improvement, 46(4), 206-214.

Ilogho, J. E. (2015). The role of picture books in promoting reading culture among Nigerian children: Implication for libraries and development of leadership qualities. International Journal of Academic Library and Information Science, 3(2), 66-71. doi: 10.14662/IJALIS2015.010

IMDB (2021). Kitap Hırsızı Film Afişi. Erişim adresi https://www. imdb.com/ title/tt0816442/? ref_=tt_mv_close

Joubert, I., Ebersöhn, L., Ferreira, R., Du Plessis, L., ve Moen, M. (2014). Establishing a reading culture in a rural secondary school: A literacy intervention with teachers. Journal of Asian and African Studies, 49(4), 399-412. doi: 10.1177/0021909613487676

Kamalova, L. A., ve Koletvinova, N. D. (2016). The problem of reading and reading culture improvement of students-bachelors of elementary education in modern high institution. International Journal of Environmental and Science Education, 11(4), 473-484. doi: 10.12973/ijese.2016.318a

Kirchheimer, O. (1941). The legal order of National Socialism. Zeitschrift für Sozialforschung, 9(3), 456-475. doi: 10.5840/zfs19419341

Kirk, T. (2002). Nazism and the working class in Austria: Industrial unrest and political dissent in the 'national community'. The United Kingdom: Cambridge University Press.

Kuhl, S. (2002). The Nazi connection: Eugenics, American racism, and German national socialism. The United Kingdom: Oxford University Press.

Leech, G. (1985). Semantics the study of meaning. The Great Britain: Penguin Books.

Leu, U. B. (2010). Die Zürcher Buch-und Lesekultur 1520 bis 1575. Zwingliana, 31, 61-90.

Loh, C. E. (2015). Building a reading culture in a Singapore school: Identifying spaces for change through a socio-spatial approach. Changing English, 22(2), 209-221. doi: 10.1080/1358684X.2015.1022509

Loh, C. E., Ellis, M., Paculdar, A. A., \& Wan, Z. H. (2017). Building a successful reading culture through the school library: A case study of a Singapore secondary school. IFLA Journal, 43(4), 335-347. doi: 10.1177/0340035217732069 
Nazi Almanya’sında Nazizm İdeolojisiyle Şekillenen Kitap Okuma Kültürünün Sinemadaki Sunumu: “Kitap Hırsızı" Filminin Göstergebilimsel Analizi

The Presentation of Book Reading Culture Shaped with Nazism Ideology in Nazi Germany in Cinema: The Semiotic Analysis of the Film "The Book Thief"

Loomis, C. P., \& Beegle, J. A. (1946). The spread of German Nazism in rural areas. American Sociological Review, 11(6), 724-734. doi: 10.2307/2087068

Lyons, M. (2008). Reading culture and writing practices in nineteenth-century France. Canada: University of Toronto Press.

Macit, M. H. (2007). Faşizm ve Nazizm. Ankara: Savaş Yayınevi.

Mason, T. (1977). National Socialism and the Working Class, 1925-May, 1933. New German Critique, (11), 49-93. doi: 10.2307/487804

McNab, C. (2015). Hitler'in Ordusu, Nazi Savaş Makinesinin Tarihi, 1939-1945. (O. Doğan, Çev.). İstanbul: Timaş Yayınları.

Misiūnas, R., \& Pischel, S. (2002). Das Buch, der Buchmarkt und die Lesekultur: Litauen im Spiegel der Literatursoziologie. Osteuropa, 52(9/10), 1143-1164.

Mühlberger, D. (2003). The social bases of Nazism, 1919-1933 (Vol. 48). The United Kingdom: Cambridge University Press.

Neumann, F. L. (2009). Behemoth: The structure and practice of national socialism, 1933-1944. The United States: Rowman \& Littlefield.

O'Brien, M. E. (2004). Nazi cinema as enchantment: The politics of entertainment in the Third Reich. The United States: Camden House.

Olasehinde, M. O., Akanmode, O. A., Alaiyemola, A. T., ve Babatunde, O. T. (2015). promoting the reading culture towards human capital and global development. English Language Teaching, 8(6), 194-200. doi: 10.5539/elt.v8n6p194

Padover, S. K. (1939). The German motion picture today: the Nazi cinema. The Public Opinion Quarterly, 3(1), 142-146.

Paskow, A. (1991). Heidegger and Nazism. Philosophy East and West, 41(4), 522-527. doi: $10.2307 / 1399648$

Passmore, K. (2014). Faşizm. (S. Gül, Çev.). Ankara: Dost Yayınları.

Patel, K. K., ve Reichardt, S. (2016). The dark side of transnationalism social engineering and Nazism, 1930s-40s. Journal of Contemporary History, 51(1), 3-21. doi: 10.1177/0022009415607956

Petro, P. (1998). Nazi cinema at the intersection of the classical and the popular. New German Critique, (74), 41-55. doi: 10.2307/488491

Pohlmann, T. (2012). Erfüllungsgehilfen? Die rolle der Bibliotheken im rahmen der Bücherverbrennungen 1933. Perspektive Bibliothek, 1(2), 193-221.

Rentschler, E. (1996). The ministry of illusion: Nazi cinema and its afterlife. The United States: Harvard University Press.

Rockmore, T. (1997). On Heidegger's Nazism and philosophy. The United States: Univ of California Press.

Rothberg, M. (2009). In the Nazi cinema: Race, visuality and identification in Fanon and Klüger. Wasafiri, 24(1), 13-20. doi: 10.1080/02690050802588984

Schlott, W. (1984). Leser und Lesekultur im sowjetischen Literaturunterricht. Osteuropa, 34(4), 246255.

Schulte-Sasse, L. (1996). Entertaining the Third Reich: Illusions of wholeness in Nazi cinema. The United States: Duke University Press.

Shandley, R. (2010). Rubble films: German cinema in shadow of 3rd Reich. The United States: Temple University Press. 
Stein, G. J. (1988). Biological science and the roots of Nazism. American Scientist, 76(1), 50-58.

Sternhell, Z. (1973). National Socialism and antisemitism: The case of Maurice Barres. Journal of Contemporary History, 8(4), 47-66. doi: 10.1177/002200947300800403

Stieg, M. (1992). The Second World War and the public libraries of Nazi Germany. Journal of Contemporary History, 27(1), 23-40. doi: 10.1177/002200949202700102

Stone, D. (2003). Responses to Nazism in Britain, 1933-1939: Before war and Holocaust. Germany: Springer.

Stranger-Johannessen, E. (2014). Promoting a reading culture through a rural community library in Uganda. IFLA Journal, 40(2), 92-101. doi: 10.1177/0340035214529732

Stuart, R. (2006). Marxism and national identity: Socialism, nationalism, and national socialism during the French fin de siècle. The United States: SUNY Press.

Sturge, K. (2002). Censorship of translated fiction in Nazi Germany. TTR: Traduction, Terminologie, Rédaction, 15(2), 153-169. doi: 10.7202/007482ar

Taylor, S. (1981). Symbol and ritual under National Socialism. British Journal of Sociology, 32(4), 504-520. doi: $10.2307 / 590130$

Umagandhi, R. ve Vinothini, M. (2017). Leech's seven types of meaning in semantics. International Journal of Multidisciplinary Research and Development, 4(3), 71-72.

Verók, A. (1999). Zur Lesekultur der Siebenbürger Sachsen im 16. und 17. Jahrhundert. Zeitschrift für Siebenbürgische Landeskunde, 22(2), 217-222.

Voigtländer, N. ve Voth, H. J. (2015). Nazi indoctrination and anti-Semitic beliefs in Germany. Proceedings of the National Academy of Sciences, 112(26), 7931-7936. doi: 10.1073/pnas.1414822112

Wagner, J. (1981). Brothers beyond the sea: National Socialism in Canada. Canada: Wilfrid Laurier University Press.

Weindling, P. (1993). Health, race and German politics between national unification and Nazism, 1870-1945. The United Kingdom: Cambridge University Press.

Wema, E. (2018). Investigating reading culture among students in higher learning institutions in Tanzania. University of Dar es Salaam Library Journal, 13(1), 4-19.

Witte, K. (1998). The indivisible legacy of Nazi cinema. New German Critique, (74), 23-30. doi: $10.2307 / 488488$

Young, J. (1998). Heidegger, philosophy, Nazism. The United Kingdom: Cambridge University Press.

Zakić, M. (2017). Ethnic Germans and national socialism in Yugoslavia in World War II. The United Kingdom: Cambridge University Press. 